\title{
Missed antenatal care follow-up and associated factors in Eastern Zone of Tigray, Northern Ethiopia
}

\author{
Amlaku Mulat ${ }^{1}$, Simachew Kassa ${ }^{1}$, Getahun Belay ${ }^{1}$, Solomon Emishaw ${ }^{2}$, Abere Yekoye ${ }^{3}$, \\ Hinsermu Bayu ${ }^{4}$, Seifu Kebede ${ }^{5}$
}

1. Department of Midwifery, College of Medicine and Health Sciences, Bahir Dar University, Ethiopia.

2. Department of Nursing, College of Medicine and Health Sciences, Bahir Dar University, Ethiopia.

3. Department of Midwifery, College of Health Sciences, Mekelle University, Ethiopia.

4. Department of Midwifery, College of Health Sciences, Arsi University, Ethiopia.

5. Department of Midwifery, College of Health Sciences, Selale University, Ethiopia.

\section{Email addresses:}

Simachew Kassa (SK): simachewkassa@yahoo.com; Getahun Belay (GB): geichbelay@gmail.com; Solomon Emishaw (SE): semishaw@gmail.com; Abere Yekoye (AB): abe2004g@gmail.com; Hinsermu Bayu (HB): henybayu1@gmail.com; Seifu Kebede (SK): seifkeb@gmail.com

\begin{abstract}
Introduction: Focused antenatal care improves the survival and health of the mother as well as the babies. However, there are real challenges in keeping the subsequent antenatal care follow up in Ethiopia. Hence, the aim of this study was to assess missed antenatal care follow up and associated factors in the Eastern zone of Tigray

Methods: Hospital based cross-sectional study was conducted among systematically selected 548 women who came for delivery services from March to April 2016. The data were collected using pre-tested and structured questionnaire through face to face exit interview. Data entry and analysis were made using EPI info version 7 software and SPSS version 20 respectively. Both binary and multiple logistic regression was performed.

Results: This study revealed that $33.4 \%$ of participants were missing their Antenatal care follow-up. Having no formal education $[\mathrm{AOR}=1.778(1.102,2.869)]$, attending primary education $[\mathrm{AOR}=1.756(1.040,2.964)]$, self-employee $[\mathrm{AOR}=1.589$ $(1.030,2.452)]$, government employee $[\mathrm{AOR}=0.503(0.503,0.953)]$, being unmarried [AOR=2.36 (1.11, 5.04)], didn't informed about institutional delivery $[\mathrm{AOR}=3.34(1.44,7.78)]$, and travel distance more than two hours to hospital $[\mathrm{AOR}=1.93$ $(1.08,3.44)]$ were factors significantly associated with missed Antenatal care follow-up.

Conclusion: The proportion of missed antenatal care follow-up was lessened as compared to local and national evidences. Nevertheless, still a coordinated effort on tracking of pregnant women who missed their antenatal care appointment is required by health policy implementers so as to increase the uptake of four complete visits.

Keywords: Antenatal care follow-up; missed antenatal care; Tigray region; Ethiopia.

DOI: https://doi.org/10.4314/ahs.v20i2.20

Cite as: Mulat A, Kassa S, Belay G, Emishaw S, Yekoye A, Bayu H, et al. Missed antenatal care follow-up and associated factors in Eastern Zone of Tigray, Northern Ethiopia. Afri Health Sci. 2020; 20(2): 690-696. https:/ / doi.org/10.4314/ abs.v20i2.20
\end{abstract}

\section{Introduction}

Globally, despite remarkable achievements towards the millennium Development Goals for maternal and child survival, each day 800 women, 7,300 stillbirths,

\section{Corresponding author: \\ Amlaku Mulat, \\ Department of Midwifery, \\ College of Medicine and Health Sciences, \\ Bahir Dar University, Ethiopia. \\ Email:amlaku78@gmail.com}

and 7,700 newborn still dying from complications occurring during pregnancy, childbirth and postpartum periods. Surprisingly $99 \%$ of maternal and newborn morbidities and mortalities are taking place in low and middle income countries ${ }^{1,2}$.

In developing countries, the proportion of pregnant women who attended at least one antenatal care visit has increased from $64 \%$ in 1990 to about $81 \%$ in 2009. However, only $39 \%$ of pregnant women attended four times or more antenatal care during 2000-2010. It has been estimated that an additional 160,000 newborn life 
could be saved through the achievement of $90 \%$ coverage of antenatal care ${ }^{3}$.

Among sub Saharan African countries, 69\% of pregnant women have at least only one antenatal care (ANC) visit. However, to achieve the full life saving potential that ANC promises for women and babies, four visits providing essential evidence based interventions often called focused antenatal care is required ${ }^{4}$. Focused ANC is more concerned with prevention, early diagnosis and treatment of general medical andregnancy associated disorders. Moreover, it gives provider the opportunity to introduce women to the health system, promote healthy behaviors during pregnancy and the postpartum period, identify and treat health problems and raise awareness of danger signs that may happen throughout pregnancy ${ }^{4,5}$.

In Ethiopia reducing maternal mortality toward millennium development goal by the end of 2015 is by far behind the target (Off Track). However, a transition from the MDGs to the Sustainable Development Goals (SDGs), attention to the reduction of maternal mortality and morbidity is now considered seriously through improvements of continuum of care for women and children as an unfinished business ${ }^{6}$.

Even though the world health organization has launched a new antenatal care model since 2016 with the aim of positive pregnancy experiences of mothers by increasing the numbers of visits from four to eight contacts, many countries including Ethiopia are not officially implementing this new ANC model so far. However, Ethiopia will implement the new WHO ANC model soon or later, after the evaluation of the current focused antenatal care model ${ }^{7}$.

High quality care during pregnancy is an essential component of the reproductive, maternal, newborn and child health continuum of care. Most health problems in pregnant women can be prevented, detected and treated by trained health professionals during antenatal care visits. However, women in Ethiopia are continuously missing their antenatal care follow-up due to so many socioeconomic problems ${ }^{8}$.

According to Ethiopian Demographic Health survey report, the country has witnessed an encouraging improvement in the ANC coverage (at least one visit) in the last decade from $28 \%$ in 2005 to $62 \%$ in 2016 . However, there are real challenges regarding early initiation of ANC and missing of subsequent antenatal care follow up. Only $32 \%$ (three out of ten women) made the recommended number of four visits according to the EDHS 20169. Therefore, the aim of this study was to assess the proportion of missed ANC follow-up and its associated factors. The finding of this study is very important to set intervention strategies to reduce missed ANC follow-up both at a national and local level so as to improve maternal and perinatal outcomes.

\section{Methods}

\section{Study design, period and area}

Hospital based cross sectional study was conducted from March to April 2016 in the Eastern Zone of Tigray Public Hospitals. Based on the 2007 Census conducted by the Central Statistical Agency of Ethiopia (CSA), this Zone has a total population of 755,34 of whom 359,638 are men and 395,705 women; 146,064 or $19.34 \%$ are urban inhabitants. There are 2 general hospitals, 4 Primary hospitals and 36 health centers resides in the Eastern zone of Tigray region. The study was conducted in six hospitals namely Adigrat, Wukiro, Atsibi, Dawan, Fatsi and Hawzen. Those hospitals are providing antenatal care and delivery service without service charge.

\section{Source and study population}

All women who came for delivery services in governmental hospitals of the eastern zone of Tigray were the source population, whereas systematically selected women who had at least one ANC follow up during their last pregnancy and came for delivery services during data collection period were considered as a study population. In this study missed antenatal care visit is operationalized as mothers who had enrolled but failed to keep subsequent antenatal care follow up until four visits during their last pregnancy. Again, both unable to read and write, and able to read and write were operationalized as 'no formal education'.

\section{Sample size determination and sampling tech- nique}

The sample size was determined using single population proportion formula by assuming $68 \%$ of women missed their ANC follow up ${ }^{10}$, level of significance $(\alpha$ $=0.05$ ) and margin of error $4 \%$. Final sample size was adjusted by adding $5 \%$ non-response rate which was 548.

Systematic sampling technique was used to select the study participants. The total sample size was distributed to each governmental hospitals to proportional to size after reviewing prior records.

Data were collected by six diploma midwives through face to face exit interview. Structured and pre-tested questionnaire was used which is prepared in Eng- 
lish and translated to Tigrigna by two native Tigrigna speakers. Both the data collectors and supervisors have been given one day training prior to data collection. Regarding the training, Emphasis was given on purposes of study, the significance and appropriate meanings of each question as well as on the art of interviewing the participants.

\section{Data processing and analysis}

Data entry was done using EPI Info 7 and data analysis was made using SPSS version 20. Variables with P-values of 0.2 and below in bivariate analysis were included in multiple logistic regression analysis and p-values of less than 0.05 were taken as a predictor variable. The degree of association between the independent and dependent variable was analyzed using odds ratio with 95\% Confidence interval.

\section{Ethical consideration}

Ethical clearance was obtained from the Institutional Review Board (IRB) of Mekelle University, College of health sciences '\#ERC 06164/2016'. Formal letter of cooperation was obtained from the Tigray Regional Health bureau and submitted to each hospital of eastern zone of Tigray. Data were collected after written consent was obtained from study participants. Confidentiality of the information was secured by removing identifiers whereas the privacy of the participants during the interview were maintained by avoiding interruptions in a secured room.

\section{Results}

\section{Socio-demographic characteristics}

All of the study participants were completed the interview. One fourth of the study participants $142(25.9 \%)$ were in the age range of $20-24$ years. The mean age of study participants was 28 years with $\mathrm{SD} \pm 6.8$. The majority of the participants were urban dwellers 339 $(61.9 \%)$, and $478(87.2 \%)$ were Orthodox Christian. Most of the participants' ethnicity was from Tigray 530 (96.75\%), Amara 10 (1.8\%) and Afar 8 (1.5\%). Five hundred fourteen participants $(93.8 \%)$ were married. One fourth of participants' monthly income were below $\leq 23.1$ USD (Table 1).

Table 1: Socio-demographic characteristics of participants in Easter zone of Tigray governmental Hospitals, $2016(n=548)$

\begin{tabular}{|c|c|c|c|}
\hline Variables & & Frequency & Percentage \\
\hline \multirow{5}{*}{ Maternal Age } & $\leq 19$ & 52 & 9.5 \\
\hline & $20-24$ & 142 & 25.9 \\
\hline & $25-29$ & 114 & 20.8 \\
\hline & $30-34$ & 109 & 19.9 \\
\hline & $\geq 35$ & 131 & 23.9 \\
\hline \multirow{4}{*}{ Religion } & Orthodox & 478 & 87.2 \\
\hline & Muslim & 33 & 6.0 \\
\hline & Protestant & 4 & 0.7 \\
\hline & Catholic & 33 & 6.0 \\
\hline \multirow{3}{*}{$\begin{array}{l}\text { Educational } \\
\text { status }\end{array}$} & No formal education & 193 & 35.2 \\
\hline & Primary education & 116 & 21.2 \\
\hline & Secondary and above & 239 & 43.6 \\
\hline \multirow{3}{*}{ Occupation } & Housewife & 278 & 50.7 \\
\hline & Self-employed & 156 & 28.5 \\
\hline & $\begin{array}{l}\text { Government } \\
\text { employees }\end{array}$ & 114 & 20.8 \\
\hline \multirow{4}{*}{$\begin{array}{l}\text { Husband's } \\
\text { occupation } \\
(n=514)\end{array}$} & Not employed & 75 & 13.7 \\
\hline & $\begin{array}{l}\text { Government } \\
\text { employee }\end{array}$ & 177 & 32.3 \\
\hline & Private employee & 181 & 33.0 \\
\hline & Other* & 81 & 14.8 \\
\hline \multirow{3}{*}{$\begin{array}{l}\text { Husband's } \\
\text { educational status } \\
(n=514)\end{array}$} & No formal education & 137 & 25.0 \\
\hline & Primary education & 123 & 22.4 \\
\hline & Secondary/higher & 254 & 46.4 \\
\hline \multirow{5}{*}{$\begin{array}{l}\text { Monthly income } \\
\text { (USD) }\end{array}$} & $\leq \$ 23.1$ & 135 & 24.6 \\
\hline & $\$ 23.2-\$ 46.3$ & 89 & 16.2 \\
\hline & $\$ 46.4-\$ 69.4$ & 49 & 8.9 \\
\hline & $\$ 69.5-\$ 92.5$ & 47 & 8.6 \\
\hline & $\geq \$ 92.6$ & 228 & 41.6 \\
\hline
\end{tabular}

*Daily laborers 
Reproductive characteristics

The mean age of participants at first pregnancy was 20.5 years with $\mathrm{SD} \pm 3.2$ and more than half $282(51.1 \%)$ were in the age range between 20 and 24 years. Regarding pregnancy intention, $511(93.2 \%)$ were planned (Table 2).

Table 2: Reproductive characteristics of participants in Easter zone of Tigray governmental Hospitals, $2016(\mathrm{n}=548)$

\begin{tabular}{llll}
\hline Variables & & Frequency & Percent \\
\hline Age at first pregnancy & $\leq 19$ & 201 & 36.7 \\
& $20-24$ & 282 & 51.5 \\
& $25-29$ & 45 & 8.2 \\
& $\geq 30$ & 20 & 3.6 \\
\hline Parity & $1-2$ & 316 & 57.7 \\
& $3-4$ & 134 & 24.5 \\
& $\geq 5$ & 98 & 17.9 \\
\hline Number of alive & 0 & 9 & 1.6 \\
children & $1-2$ & 324 & 59.1 \\
& $3-4$ & 134 & 24.5 \\
& $\geq 5$ & 81 & 14.8 \\
\hline Number of still births & 0 & 484 & 88.3 \\
& $1-2$ & 64 & 11.7 \\
\hline History of abortion & No & 459 & 83.8 \\
& Yes & 89 & 16.2 \\
\hline Type of abortion (n=89) & Induced & 22 & 24.7 \\
& Spontaneous & 67 & 75.3 \\
\hline Were & No & 37 & 6.8 \\
the pregnancy planned? & & & \\
& Yes & 511 & 93.2 \\
\hline Reasons for unplanned & Husband enforcement & 3 & \\
Pregnancy (n=37) & Accidental & & \\
& conception & 34 & 6.5 \\
\hline
\end{tabular}

Proportion of Missed Antenatal care follow-up

Among the total participants $183(33.4 \%)$ (95\% CI: (29.6-37.6\%) were missing their subsequent antenatal care follow-up. Only 365 (66.6\%) of them had four and above Antenatal care follow up during their last pregnancy (Figure 1).

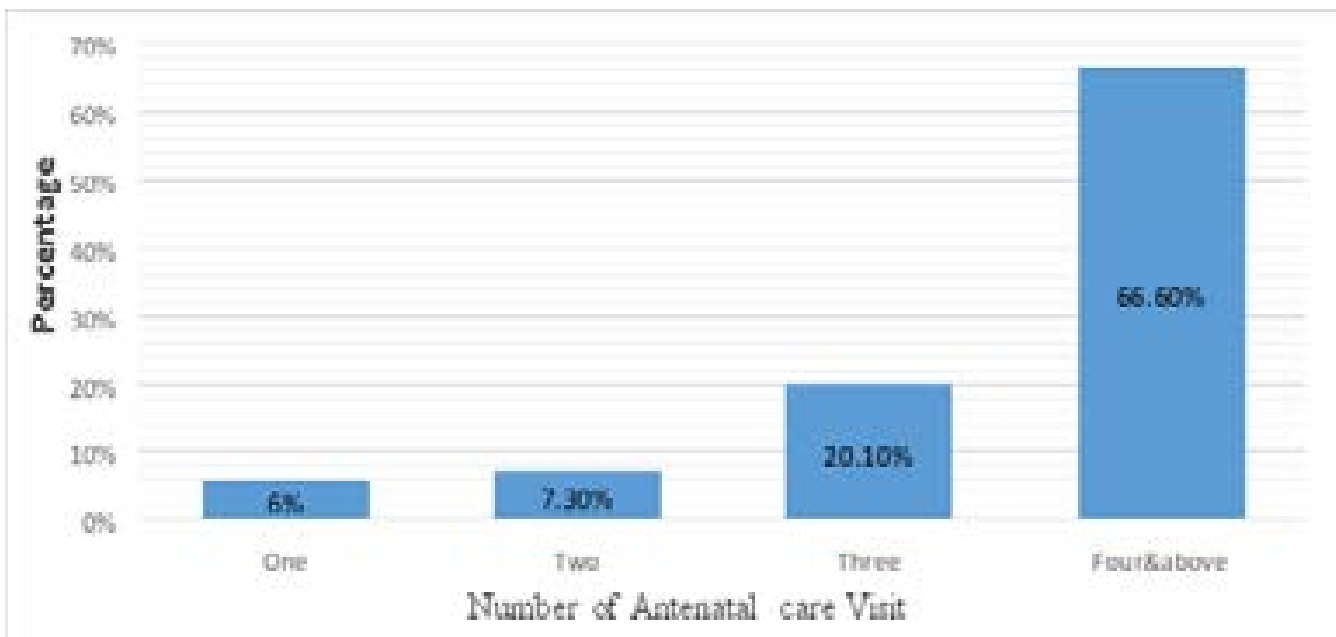

Figure 1: Proportion of participants across each antenatal care visit in Easter zone of Tigray governmental Hospitals, 2016 
Four hundred nine $(74.6 \%)$ initiate their ANC follow up between 14 to 26 weeks of gestation; 93 (17\%) before 13 weeks, and the rest $46(8.4 \%)$ between 22 to 40 weeks of pregnancy. Reasons for missing ANC visit were feeling being healthy 183 (80.3\%), busy 143 (62.7\%), far from health institution $122(53.5 \%)$, long waiting time $6(2.6 \%)$, and $18(18.9 \%)$ for other reasons such as poor quality of care and negative experiences.

\section{Associated factors of Missed ANC Follow up}

Using binary logistic regression; Educational status, occupation, marital status, planning of their pregnancy, advised about institutional delivery, history of stillbirth travel distance to institutions, and means of transportation were found to have a statically significant association with missing antenatal care appointment.

Those variables were entered once into backward stepwise multiple logistic regression model. After adjustment, no formal education $[A O R=1.778$ (1.102, $2.869)]$, attending primary education $[\mathrm{AOR}=1.756$ $(1.040,2.964)]$, self-employee $[\mathrm{AOR}=1.589$ (1.030, $2.452)]$, government employee $[\mathrm{AOR}=0.503$ (0.503, $0.953)]$, unmarried $[\mathrm{AOR}=2.36(1.11,5.04)]$, didn't informed about institutional delivery $[\mathrm{AOR}=3.34(1.44$, 7.78)], and travel distance more than two hours to hospital $[A O R=1.93(1.08,3.44)]$ were found to be independent predictors of missed antenatal care (Table 3).

Table 3: Binary and multiple logistic regression results regarding associated factors of missed Antenatal care follow up in the eastern zone of Tigray, 2016

\begin{tabular}{|c|c|c|c|c|c|c|}
\hline \multicolumn{2}{|c|}{ Variables } & \multicolumn{2}{|c|}{ No of visits } & \multirow[b]{2}{*}{ COR with $95 \%$ CI } & \multirow[b]{2}{*}{ AOR with $95 \%$ CI } & \multirow{2}{*}{$\begin{array}{l}P \text { - } \\
\text { value }\end{array}$} \\
\hline & & $<4$ & $\geq 4$ & & & \\
\hline \multirow[t]{3}{*}{$\begin{array}{l}\text { Educational } \\
\text { status }\end{array}$} & $\begin{array}{l}\text { No formal } \\
\text { education }\end{array}$ & 86 & 107 & $2.890(1.902,4.392)$ & $1.778(1.102,2.869)$ & .018 \\
\hline & Primary education & 45 & 71 & $2.279(1.405,3.697)$ & $\begin{array}{l}1.756(1.040, \\
2.964)\end{array}$ & .035 \\
\hline & Secondary/higher & 52 & 187 & 1 & 1 & \\
\hline \multirow[t]{3}{*}{ Occupation } & Housewife & 99 & 179 & 1 & 1 & \\
\hline & Self-employed & 68 & 88 & $1.397(.936,2.085)$ & $1.589(1.030,2.452)$ & .036 \\
\hline & $\begin{array}{l}\text { Government } \\
\text { employees }\end{array}$ & 16 & 98 & $0.295(0.165,0.529)$ & $0.503(0.503,0.953)$ & .035 \\
\hline \multirow[t]{2}{*}{ Marital status } & Unmarried & 21 & 13 & $3.510(1.715,7.184)$ & $2.365(1.110,5.040$ & .026 \\
\hline & Married & 162 & 352 & 1 & 1 & \\
\hline \multirow[t]{2}{*}{ No of still birth } & 0 & 153 & 331 & 1 & 1 & \\
\hline & $1-2$ & 30 & 34 & $1.909(1.127,3.233)$ & $1,153(0.627,2.120)$ & .647 \\
\hline \multirow{2}{*}{$\begin{array}{l}\text { Were } \\
\text { the PX planned? }\end{array}$} & No & 20 & 17 & 1 & 1 & \\
\hline & Yes & 163 & 348 & $0.398(0.203,0.780)$ & $1.054(0.437,2.541)$ & .908 \\
\hline \multirow{2}{*}{$\begin{array}{l}\text { Informed about } \\
\text { benefit of ID }\end{array}$} & No & 19 & 9 & $4.583(2.030,10.347)$ & $3.341(1.435,7.776)$ & .005 \\
\hline & Yes & 164 & 356 & 1 & 1 & \\
\hline \multirow{2}{*}{$\begin{array}{l}\text { How long } \\
\text { time took }\end{array}$} & $\leq 120 \mathrm{~min}$ & 145 & 332 & 1 & 1 & \\
\hline & $\geq 121 \mathrm{~min}$ & 38 & 33 & $2.637(1.590,4.371)$ & $1.929(1.083,3.437)$ & .026 \\
\hline \multirow{2}{*}{$\begin{array}{l}\text { Means of } \\
\text { transportation }\end{array}$} & On foot & 132 & 297 & $0.593(0.391,0.899)$ & $0.785(0.492,1.253)$ & .310 \\
\hline & By vehicle & 58 & 68 & 1 & 1 & \\
\hline
\end{tabular}

$\mathrm{ID}=$ institutional delivery, $\mathrm{PX}=$ pregnancy

\section{Discussion}

This study depicted that about $33.4 \%$ of participants were missing their antenatal care follow-up. The finding of this study was much less than the report of EDHS, 2016 which was $68 \%$ of women were missing their antenatal care appointments 9 . This difference may be due to the governments strive to ensure the proper operations of focused antenatal care and auditing system. Besides the introduction of compassionate and re- spectful maternal care could have also a positive impact for mothers not miss their consecutive antenatal care appointments. Adverse pregnancy outcomes can be minimized or avoided altogether if antenatal care has received early in the pregnancy and continued through delivery.

According to this study, a small proportion of women which were only $17 \%$ of them had initiated their first ANC visit during the first trimester before 13 weeks of gestation. 
The proportion of women who initiated their ANC visit during first trimester in this study were slightly higher than the proportion of women in Kenya $12 \%$ and Malawi $15 \%{ }^{11}$. On the other hand the finding was slightly lower as compare to the study done in china which was $19.7 \%$ and study done in Addis Ababa $22.4 \%$ of them were initiated their ANC before 13 weeks of gestation $^{12,13}$.

Having no formal education and primary education increase odds of missing antenatal care follow-up by a factor of 1.778 and 1.756, [AOR=1.778 $(1.102,2.869)]$ and $[\mathrm{AOR}=1.756(1.040,2.964)]$ respectively. Other similar studies reported that the women's level of education has a positive impact on adequate ANC service utilization ${ }^{14-16}$. This may be explained by the fact that educated women are more knowledgeable on the importance of maternal health services; they may have access to written information and may have a more modern cultural perspective. Moreover; Education is an opportunity to empower women; and empowered women have greater confidence and greater decision making power to use modern health care services for themselves and for their children.

This study showed that self-employed mothers are 1.589 times more likely to miss their Antenatal care appointments as compared to house wives $[\mathrm{AOR}=1.589$ $(1.030,2.452]$. Similarly unmarried women were 2.365 times more likely to miss antenatal care appointments as compare to married women $[\mathrm{AOR}=2.365(1.110$, 5.040)].

Consistent to this finding, a study done in Addis Ababa on adequacy of ANC among slum residents reported that unmarried women and those cohabiting/living together were 61 and $62 \%$ less likely to have four or more antenatal visits compared to their married counterparts ${ }^{17}$. This can be explained by husband role and contribution to ANC service use through financial support, accompaniment of mothers to in ANC clinic, and ensuring adherence to ANC. For women who were not informed about benefit of institutional delivery during their first antenatal care visit; the odds of missing their ANC appointments increased by a factor of 3.341 $[\mathrm{AOR}=3.341(1.435,7.776)]$.

Proximity to a health facility is another key factor involved in improving access to maternal health care service. The results of this study confirm that women who travel greater than two hours walking to into hospital were nearly two times more likely to miss an ANC appointment as compared to those traveled less than two hours $[A O R=1.929(1.083,3.437)]$. Similar to this finding is a study done in South Africa that reported increased distance to ANC services was 3.3 times more likely to negatively impact uptake of ANC visits ${ }^{16,18}$. This might be related to the fact that pregnant women get difficulties to walk long distance or use different transportation services to get into institutions and receive prenatal care on the appointment days. Moreover; living closer to health institutions may promote antenatal care use as costs incurred for transportation and absence from work might be minimized.

Limitation of this study,

it doesn't address the qualitative aspects like detailed reasons why mothers missed their ANC follow-up. Therefore, it is open for researchers to conduct a qualitative study on why women missed their subsequent Antenatal care follow-up.

\section{Conclusion}

The proportion of missed Antenatal care follow-up was lessened as compared to local and national evidences.

Educational level, occupation, information about the benefit of institutional delivery and travel distance to hospitals were found to have a statistically significant association with the missing antenatal care follow-up. Therefore, a coordinated effort on tracking of pregnant women who missed their antenatal care appointment is needed by health policy implementers so as to increase the uptake of four complete visits.

\section{Abbreviation}

ANC: Antenatal Care; AOR: Adjusted Odds Ratio; EDHS: Ethiopia Demographic Health Survey; IRB: Institutional Review Board; WHO: World Health Organization.

\section{Acknowledgement}

The authors would like to appreciate Mekelle University for funding this research project. We would like to thank all study participants and data collectors for their contribution in the success of this work.

\section{Authors' contribution}

AM contributed in inception, design, analysis, interpretation, and manuscript drafting for publication. AY\&SE carry out the data analysis, interpretation and first draft of the manuscript. HB, SK, GB \& SK contributed on design, interpretation, and revised draft of the manuscript. All authors read and approve the final manuscript.

\section{Conflict of interest}

The authors declare that there is no conflict of interests regarding the publication of this paper.

African Health Sciences Vol 20 Issue 2, June, 2020 


\section{Reference}

1. Organization WH, UNICEF. Trends in maternal mortality: 1990 to 2013: estimates by WHO, UNICEF, UNFPA, The World Bank and the United Nations Population Division: executive summary. 2014.

2. Chou D, Daelmans B, Jolivet RR, Kinney M, Say L. Ending preventable maternal and newborn mortality and stillbirths. BMJ. 2015;351: h4255.

3. Kuuire VZ, Kangmennaang J, Atuoye KN, Antabe $\mathrm{R}$, Boamah SA, Vercillo S, et al. Timing and utilization of antenatal care service in Nigeria and Malawi. Global Public Health. 2017;12(6):711-27.

4. AbouZahr C, Wardlaw T. Antenatal care in developing countries: Promises, achievements and missed opportunities-an analysis of trends, levels and differentials, 1990-2001: World Health Organization; 2003.

5. Campbell OM, Graham WJ, group LMSSs. Strategies for reducing maternal mortality: getting on with what works. The Lancet. 2006;368(9543):1284-99.

6. UN. Transforming our world: the 2030 Agenda for Sustainable Development. New York from 25 to 27 September 2015.

7. Organization WH. WHO recommendations for antenatal care for a positive pregnancy experience: World Health Organization; 2016.

8. Organization WH. WHO antenatal care randomized trial: manual for the implementation of the new model: WHO; 2002.

9. ICF CSACEa. Ethiopia Demographic and Health Survey 2016: Key Indicators Report. . Addis Ababa, Ethiopia, and Rockville, Maryland, USA CSA and ICF. 2016.

10. Economy CSA-MoF. Ethiopia Mini Demographic and Health Survey 2014; ETH-CSA-EMDHS2014-v1.0.
11. Pell C, Meñaca A, Were F, Afrah NA, Chatio S, Manda-Taylor L, et al. Factors affecting antenatal care attendance: results from qualitative studies in Ghana, Kenya and Malawi. PloS One. 2013;8 (1): e53747.

12. Zhao Q, Huang ZJ, Yang S, Pan J, Smith B, Xu B. The utilization of antenatal care among rural-to-urban migrant women in Shanghai: a hospital-based cross-sectional study. BMC Public Health. 2012;12(1):1.

13. Bayou YT, Mashalla YS, Thupayagale-Tshweneagae G. The adequacy of antenatal care services among slum residents in Addis Ababa, Ethiopia. BMC Pregnancy and Childbirth. 2016;16(1):1.

14. Birmeta K, Dibaba Y, Woldeyohannes D. Determinants of maternal health care utilization in Holeta town, central Ethiopia. BMC Health Services Research. 2013;13(1):256.

15. Tarekegn SM, Lieberman LS, Giedraitis V. Determinants of maternal health service utilization in Ethiopia: analysis of the 2011 Ethiopian Demographic and Health Survey. BMC Pregnancy and Childbirth. 2014;14(1):161.

16. Onasoga OA, Afolayan JA, Oladimeij BD. Factors influencing utilization of antenatal care services among pregnant women in Ife Central LGA, Osun State, Nigeria. Advances in Applied Science Research. 2012;3(3):130915.

17. Bayou YT, Mashalla YS, Thupayagale-Tshweneagae G. The adequacy of antenatal care services among slum residents in Addis Ababa, Ethiopia. BMC Pregnancy and Childbirth. 2016;16(1):142.

18. Worku EB, Woldesenbet SA. Factors that Influence Teenage Antenatal Care Utilization in John Taolo Gaetsewe (JTG) District of Northern Cape Province, South Africa: Underscoring the Need for Tackling Social Determinants of Health. International Journal of $M C H$ and AIDS. 2016;5(2):134. 